\title{
The Fine Structure of Bacteriophages
}

\author{
By D. E. BRADLEY \\ Research Laboratory, Associated Electrical Industries, Aldermaston Court, \\ Aldermaston, Berkshire \\ AND D. KAY \\ British Empire Cancer Campaign Unit for Virus Research, Sir William Dunn \\ School of Pathology, University of Oxford
}

(Received 2 June 1960)

\section{SUMMARY}

The 'negative contrast' method for the preparation of viruses for electron microscopy was used to study 22 different bacteriophages. A great variety of features is described, leading to some morphological grouping. The use of uranyl acetate on coli phage $\mathbf{T} 5$ revealed subunit structure in both the head and tail, features not shown by the conventional phosphotungstic acid treatment.

\section{INTRODUCTION}

Until the application of the 'negative contrast' technique to the electron microscopy of bacteriophage particles by Brenner et al. (1959), all published electron micrographs had been obtained of shadowed or, occasionally, of sectioned specimens. The smallest resolvable detail in shadowed specimens consists of the discrete crystallites of the shadowing material so that the fine structure of the phage particles themselves is obscured rather than revealed. On the other hand, 'negative contrast' methods are capable of making full use of the high resolving power (10 $\AA$ or less) of modern electron microscopes, thus permitting the examination of hitherto invisible details of bacteriophage structure. An examination of the literature shows that the most intensively studied bacteriophage from every point of view is the coli phage $\mathbf{T} 2$ which was, incidentally, the subject of the highly informative work of Brenner et al. (1959). In comparison with coli phage T2 little is known about other phages, particularly those outside the coli group. It was therefore considered of value to study a variety of phages now that higher resolution is available. The authors of the present paper have not attempted to examine phages active against all the bacterial species which possess them. A collection of $\mathbf{2 2}$ different phages is described; they are active on the following bacteria: the coli-typhoid group, Staphylococcus, Streptococcus lactis, Pseudomonas aeruginosa and Brucella abortus. A wide variety of structures has been observed but certain clear groupings into morphological types can be made.

\section{METHODS \\ Bacteriophages used}

Coli-typhoid phages. The three phages of the coli $\mathbf{T}$ group (of which there are seven altogether), T 1, T 3 and T 5, were obtained some years ago from Professor T. F. Anderson. Stocks for electron microscopy were prepared on Escherichia coli $\mathbf{B}$ growing in 
a defined medium supplemented with $0.00025 \mathrm{M}$-calcium chloride in the case of $\mathrm{T} 1$ and $\mathrm{T} 5$ (Kay, 1959). Phages $11 \mathrm{~F}, \mathrm{C} 4, \mathrm{~S} 1 \mathrm{BL}, \mathrm{S} 6 \mathrm{BL}, 66 \mathrm{~F}, 3 \mathrm{~T}^{+}$were isolated from samples of raw and effluent sewage, kindly supplied by the Oxford sewage works, by growth and selection of phages on certain coli and typhoid bacteria (Fildes \& Kay, 1957). The unadapted Vi phage no. 1 was obtained some time ago from the late Dr A. Felix. Typhoid phages 1 and 2 were described by Fildes \& Kay (1955).

Staphylococcus phages. Six of the Staphylococcus typing phages were kindly supplied by Dr R. E. O. Williams (Central Public Health Laboratories, Colindale, London, N.W. 9). They were numbered 3B, 6, 52, 71, 77 and 187. The suspensions were used as supplied in broth. No attempt was made to grow more of these phages.

Streptococcus lactis phage. This was kindly supplied by Mr B. Reiter (National Institute for Research in Dairying, Shinfield, Reading).

Pseudomonas aeruginosa phages. We are indebted to Dr Lois Dickinson (Boots Pure Drug Co. Ltd., Nottingham) for a supply of three phages, $\mathrm{Pa}, \mathrm{Pc}$ and $\mathrm{Pz}$. Pa and $\mathrm{Pz}$ are lysogenic phages and $\mathrm{Pc}$ is a virulent mutant isolated from $\mathrm{Pz}$. Stocks of these phages were prepared on a strain of $P$. aeruginosa $\mathrm{C} 10$ also supplied by Dr Dickinson.

Brucella phage. This phage was supplied by Dr W. J. Brinley Morgan (Veterinary Research Station, Ministry of Agriculture, Fisheries and Food, Weybridge, Surrey) as a suspension in broth. It is active on a strain of Brucella abortus and is referred to in greater detail by Brinley Morgan, Kay \& Bradley (1960).

\section{Preparation of specimens for the electron microscope}

The technique used was essentially that of Brenner et al. (1959), though the use of potassium phosphomolybdate and uranyl acetate was suggested by Nixon (1960). The principle is that the phage particles are embedded in a dried microdroplet of electron-dense material on a suitable support film, and examined directly in the electron microscope. The details of the method as used are as follows.

The phage suspension in nutrient broth or in phosphate buffer $(0.033 \mathrm{M}, \mathrm{pH} \mathrm{7.6)}$ was first centrifuged at low speed to remove bacterial debris. The phage particles themselves were then sedimented at about $8000 \mathrm{~g}$ and the supernatant fluid discarded. The pellet was resuspended in a solution of potassium phosphotungstate or phosphomolybdate prepared by adjusting a $1 \%(\mathrm{w} / \mathrm{v})$ solution of the appropriate acid with potassium hydroxide to $\mathrm{pH}$ 7.2. An electron microscope specimen support grid was coated with a carbon film containing small holes as an aid to focusing, washed in chloroform to remove grease, and then touched on to the surface of the phage suspension so that it was covered with a thin film of liquid. After drying in air the specimen was ready for examination.

In the case of the calcium-dependent phage $\mathrm{T} 5$, uranyl acetate was used instead of potassium phosphotungstate or phosphomolybdate. A $1 \%(w / v)$ solution of uranyl acetate in water is at $c . \mathrm{pH} 3 \cdot 5$, and this $\mathrm{pH}$ value cannot be increased without causing a precipitate. It was therefore necessary to use the solution of this low $\mathrm{pH}$ value for the final embedding. To decrease the chance of osmotic effects the phage was transferred through an intermediate solution of ammonium acetate $(\mathrm{pH} \mathbf{5 \cdot 0}$, $0.033 \mathrm{M}$ ) from the phosphate buffer, by centrifugation, before finally suspending in the uranyl acetate solution. This procedure also removed traces of phosphate which 
would have precipitated uranium. Both the ammonium acetate and the uranyl acetate contained $0.0005 \mathrm{M}$-calcium chloride in an attempt to decrease the inactivation of the phage.
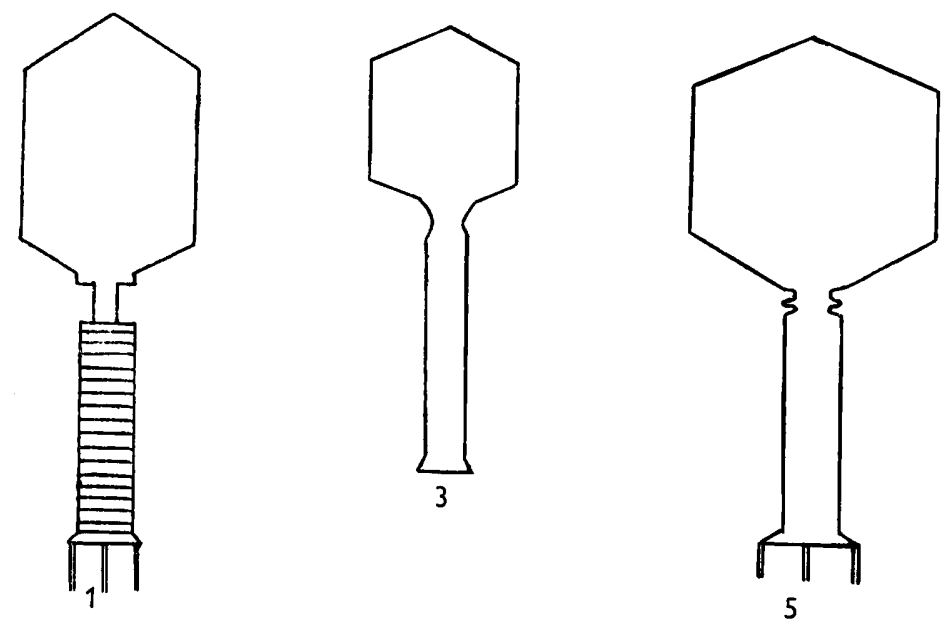

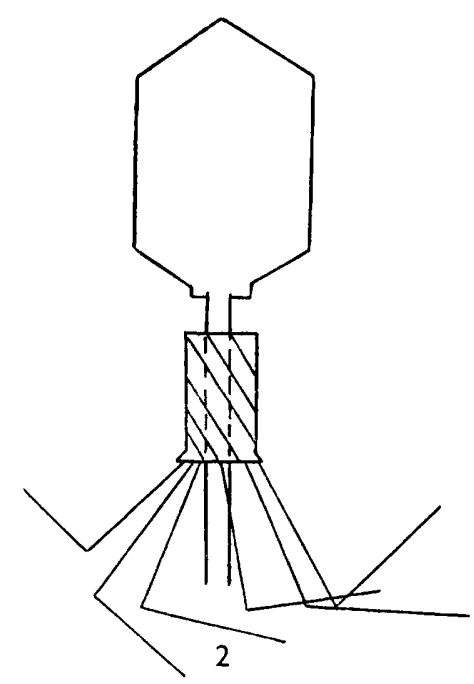

Fig. 1. T2 type, active. Fig. 2. T2 type, inactive. Fig. 3. Phage 2, active.

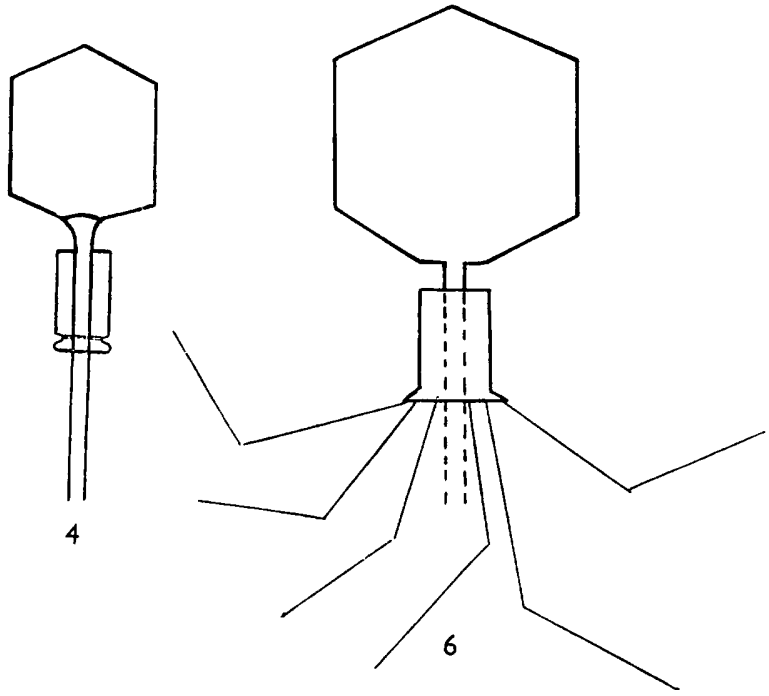

Fig. 4. Phage 2, inactive.

Fig. 5. Phage Vil, active.

Fig. 6. Phage Vi 1, inactive.

\section{Description of the phage particle structures}

It is generally agreed that all phages so far examined contain deoxyribonucleic acid (DNA) and that this material, which may amount to $50 \%$ of the weight of the phage, is contained in the head of the particle. DNA as such cannot be recognized in electron micrographs of phage, but its presence or absence in the phage head can be observed with some certainty. By using the 'negative contrast' technique, the phage particles appear as electron-transparent objects set in an electron-dense 
surround which contains the phosphotungstate. This indicates that the phosphotungstate is not absorbed by the particles and thus a considerable contrast difference is obtained. Should the phage particle have lost its DNA, this will be replaced in the head by phosphotungstate which diffuses through the head membrane. Thus the contrast provided by an empty head will be much less than that provided by one full of DNA. It is therefore possible to distinguish between intact and changed
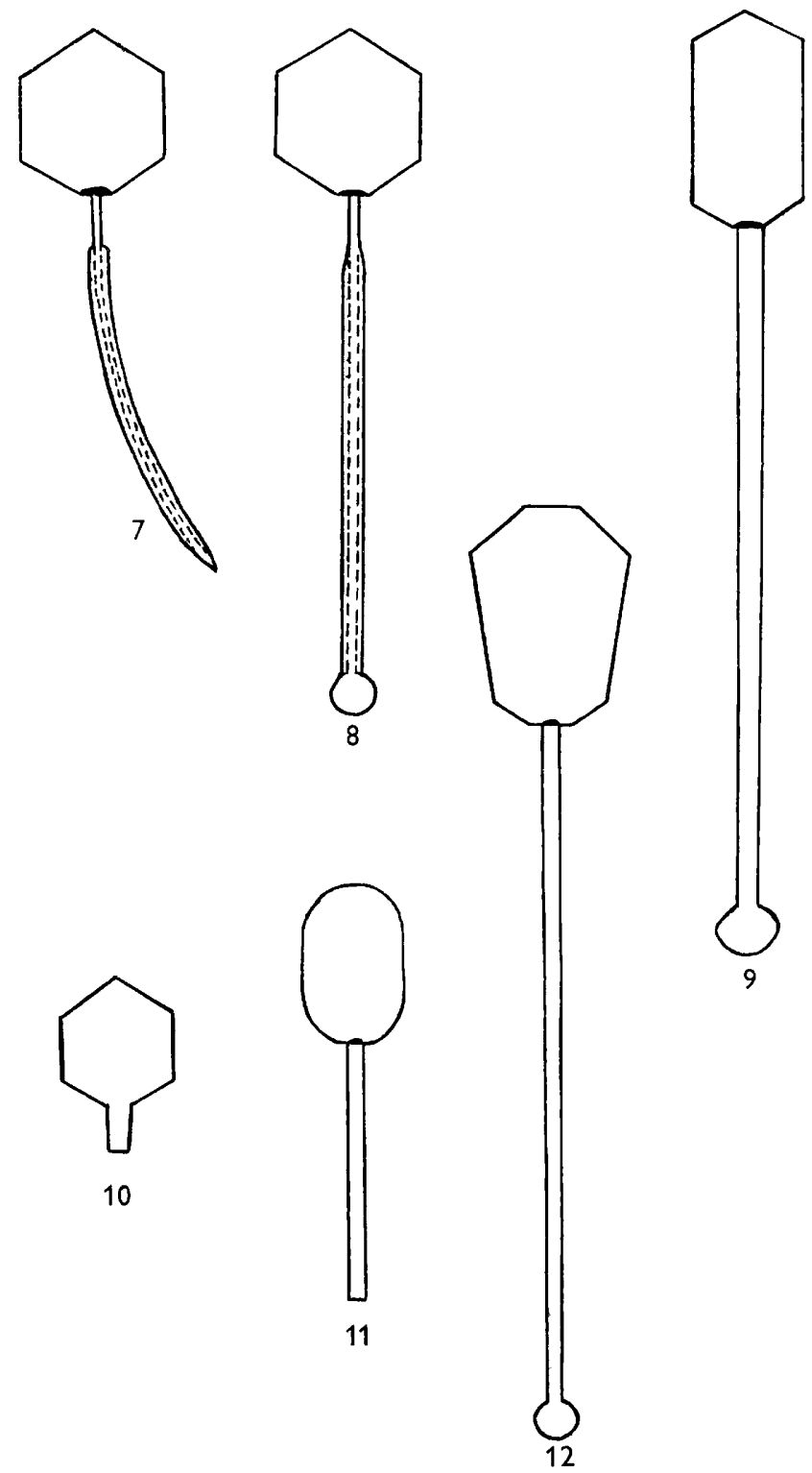

10

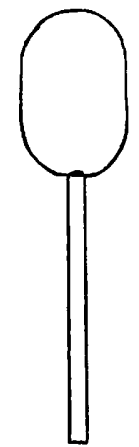

Fig. 7. SBL group, phage 1, phages T1 and T5; general appearance only; the dimensions vary. Fig. 8. Phages Pc, 187, 77, etc., general appearance only; the dimensions vary.

Fig. 9. Phage 6.

Fig. 10. Phages T3 and Brucella phage.

Fig. 11. Phage 3ML.

Fig. 12. Phage $3 \mathrm{~B}$. 
particles in the electron microscope. It seems likely that the changed particles correspond in appearance to those which have injected their DNA into a host cell.

The electron micrographs of the phages clearly show the morphological details, but for clarity the more important features are illustrated in the line drawings (Figs. 1-12).

Table 1. Dimensions of phage particles

\begin{tabular}{|c|c|c|c|c|}
\hline Phage & Head* $^{*}(\mathbf{A})$ & Tail length $(\AA)$ & $\begin{array}{c}\text { Sheath } \\
\text { width } \dagger(\mathbb{A})\end{array}$ & $\begin{array}{c}\text { Core } \\
\text { width }(\AA)\end{array}$ \\
\hline Coli T 2\% & $\begin{array}{c}1000 \times 700 \\
(950 \times 650) \S\end{array}$ & $\begin{array}{l}1100 \text { (periodicity } 30) \\
(1000)\end{array}$ & $\mathbf{2 5 0}$ & 70 \\
\hline Typhoid 3T+ & $900 \times 650$ & 950 (periodicity 30) & 150 & 60 \\
\hline Typhoid C4 & $1000 \times 750$ & 1000 (periodicity 30) & 200 & 70 \\
\hline Typhoid II F & $900 \times 650$ & 920 (periodicity 30) & 150 & 60 \\
\hline Typhoid 66F & $900 \times 700$ & 950 & 150 & - \\
\hline Typhoid phage 2 & $720 \times 660$ & 1100 & 220 & 100 \\
\hline Typhoid Vi 1 & $900 \times 950$ & 1100 & 180 & - \\
\hline Coli T5 & $750 \times 750(650)$ & $\begin{array}{l}1800 \text { (periodicity } 44) \\
(1700)\end{array}$ & 120 & 30 \\
\hline Typhoid phage 1 & $750 \times 750$ & 1800 & 90 & - \\
\hline Coli T1 & $620 \times 620(500)$ & $1300(1500)$ & 100 & 30 \\
\hline Typhoid S1 BL & $500 \times 500$ & 1300 & 100 & 40 \\
\hline Pseudomonas $\{\mathrm{Pc}$ & $650 \times 650$ & 1600 (knob 200) & 110 & 60 \\
\hline 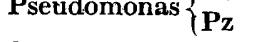 & $650 \times 650$ & 1600 (knob 200) & 100 & - \\
\hline Staphylococcus 187 & $600 \times 600$ & 1800 (knob 320) & 120 & - \\
\hline Staphylococcus 77 & $600 \times 600$ & 2500 (knob 200) & 100 & - \\
\hline Staphylococcus 3B & $800 \times 600$ & 3000 (knob 200) & 100 & - \\
\hline Staphylococcus 6 & $920 \times 400$ & $3000($ knob 200) & 100 & - \\
\hline Staphylococcus 71 & $630 \times 630$ & $1700(\mathrm{knob}-)$ & 100 & - \\
\hline Staphylococcus 52 & $550 \times 550$ & 1500 (knob - $)$ & 110 & - \\
\hline Streptococcus 3ML & $550 \times 400$ & 1000 & 90 & 一 \\
\hline Coli T3 & $550 \times 550(470)$ & $150(150)$ & 80 & - \\
\hline Brucella & $550 \times 550$ & 150 & - & - \\
\hline Coli S13 & 250 & - & - & - \\
\hline
\end{tabular}

* The dimension from the apex to the tail joint is given first, then the width.

$\dagger$ Sheaths were measured in the uneontraeted state; where there is no sheath the tail diameter is given.

$\ddagger$ After Brenner et al. (1959).

$\$$ Bracketed figures denote dimensions obtained from shadowed preparations except in the cases of tail periodicity and knob dimensions.

\section{Group 1. Phages with contractile tail sheaths}

(a) Coli-typhoid phages 3T ${ }^{+}, \mathrm{C} 4,11 \mathrm{~F}, 66 \mathrm{~F}$ (Figs. 1, 2 and Pl. 1, figs. 1-4)

These phages are all morphologically identical except for minor differences in dimensions (Table 1), and are indistinguishable from coli phage T2 (Brenner et al. 1959). The chief features are the bipyramidal hexagonal prismatic head, the contractile tail sheath with its cross-striations (spacing $30 \AA$ ) shown well in Pl. 1, fig. 3, and the terminal base-plate with several prongs (three are shown in Pl. 1, fig. 2). The central hollow tubular core of the tail is shown in Pl. 1, fig. 4, after contraction of the sheath has occurred. A minor feature is the constriction of the tail at its junction with the head. The appearance of the heads in Pl. 1, figs. 1 and 2, suggest that the DNA is still present, but has been lost in Pl. 1, fig. 4. The head in Pl. 4, fig. 3, also contains the DNA, but the contrast in Pl. 1, figs. 3 and 4, is lower because a rather thin film of potassium phosphomolybdate (this is more transparent than phosphotungstate) was used. 
(b) Typhoid phage 2 (Figs. 3, 4 and Pl. 1, figs. 5-7)

This phage is similar in many ways to the 3-T2 group, but the morphological differences are distinct. First, the head is much shorter (Table 1 ) and is of a different shape. The well-preserved empty heads in Pl. 1, figs. 6 and 7, appear to be octahedra, although the possibility that they are icosahedra cannot be ruled out. The tail is the same length as in the 3-T 2 group, and also consists of a core surrounded by a sheath shown contracted in Pl. 1, figs. 6 and 7. No cross-striations can be seen on the uncontracted sheath in this preparation (Pl. 1, fig. 5), although this does not necessarily mean that they are absent, since they are not always visible in coli phage $\mathbf{T} 2$ preparations. The sheaths are readily detachable from the core and three are shown in Pl. 1, fig. 7. One is lying almost end-on and exhibits the cog-wheel appearance associated with the 3-T2 group sheaths. It thus seems likely that the re-arrangement of the sheath molecules to achieve contraction is similar to that in phage T2 as suggested by Brenner et al. (1959). There is a distinct base-plate attached to the sheath, but unlike coli phage $\mathrm{T} 2$ it possesses no tail pins.

\section{(c) Vi phage 1 (Figs. 5, 6 and Pl. 1, fig. 8)}

This phage has a regular polyhedral head like that of phage 2 but is significantly larger (Table 1). Its tail carries a very conspicuous base-plate.

\section{Group 2. Phages without contractile tail sheaths}

(a) Coli phage T 5, typhoid phage 1 (Fig. 7, and Pl. 1, fig. 9, and Pl. 2, figs. 10-13)

These two phages are morphologically identical and only one (T5) is shown. It is the largest in this group (see Table 1) and is calcium-dependent. Here a striking difference was found in appearance, as between particles stained with phosphotungstate and those treated by the experimental uranyl acetate staining described above. No structure is visible on the tail or head in the standard preparation (Pl. 1, fig. 9), but the uranyl acetate preparation (Pl. 2, figs. 10-13) shows up crossstriations on the tail, with a period of $44 \AA$, rather larger than in the sheath of coli phage T2 (30 $\AA$ ). A central core is visible as in the standard preparation. It is not fully understood why the striations appeared in one preparation only, but two explanations are considered possible. The first is that under negative contrast conditions (as with phosphotungstate) the tail subunits are invisible because insufficient contrast is produced. In the case of uranyl acetate, however, it is possible that uranium has been attached to the protein subunits and a true stain obtained in addition to negative contrast; thus the subunits would show in one case and not the other. The second possible explanation is that the subunits are partially disorganized by the change in $\mathrm{pH}$ values which the particle has suffered, so that they are rendered visible by a structural change. In either case there is no doubt that the molecular organization of the tail is shown. A disorganized tail (Pl. 2, fig. 10, arrowed) suggests that the subunits are of tubular form.

Subunits are also visible in the head in the uranyl acetate preparation shown in Pl. 2, figs. 10-13. It is clear from these electron micrographs that the molecular structure of the head has undergone considerable disorganization, due no doubt to the low $\mathrm{pH}$ value. It seems that it is only this disorganization which enables the 
subunits to be seen, since in a fully organized state they are probably too closely packed. They appear to be broadly similar in appearance to those found on the surface of Herpes virus by Horne, Brenner, Waterson \& Wildy (1959), though very much smaller. They consist of hollow tubes (similar to the tail subunits) about $100 \AA$ long and $50 \AA$ in diameter. It is not possible to state the method of packing as the degree of disorganization is too great, though some regularity is visible in Pl. 2, fig. 11. Most of the subunits in Pl. 2, fig. 12, are visible end-on, and those in Pl. 2, fig. 13, are lying on their sides. It is clear that $\mathrm{T} 5$ would repay further more detailed investigation.

\section{(b) Coli phage T1 and typhoid phage S $1 \mathrm{BL}$ (Fig. 7, and Pl. 3, figs. 14-17)}

These two types are morphologically identical save for a slight difference in the size of the head (Table 1) and in the absence of the thin neck between the head and the tail in 71. Plate 3, figs. 14 and 15 , show that the tail of phage S1 BL is built up of an inner hollow tube, surrounded by a sheath which shows no signs of contraction even when the DNA has been released as in Pl. 3, fig. 14. At its junction with the head a small knob is visible. A well-marked pattern is visible in the deflated head of $\mathrm{S} 1 \mathrm{BL}$ in $\mathrm{Pl}$. 3, fig. 14. This pattern is visible in several other particles which have lost their DNA (Pl. 3, figs. 17 and 19-21).

(c) Pseudomonas phages $\mathrm{Pc}$ and $\mathrm{Pz}$, Staphylococcus phages 187, 77, 3B, 6 (Figs. 8, 9, 12, and Pl. 3, figs. 18-23, and Pl. 4, figs. 24-30)

These can be subdivided into phages with very long tails $(6,3 \mathrm{~B}, 77)$ and those with shorter tails (187, $\mathrm{Pc}, \mathrm{Pz}$ ). Of the latter $\mathrm{Pc}$ is identical with $\mathrm{Pz}$. Phages 187 and $\mathrm{T} 1$ resemble these two, apart from the terminal knob. The heads are regular polyhedra and the tails are hollow tubes. The lumen of the tail can be seen when the DNA has been discharged (Pl. 3, fig. 20), but cannot be seen when the DNA is present (Pl. 3, fig. 18).

The tail knobs on phages 187 and 71 are much larger than those of Pc and in Pl. 3, fig. 23 (phage 187) the knobs have a six-sided appearance.

Phage 77 (Pl. 3, fig. 19) has an unusually long tail and when the DNA has been discharged can be seen to be hollow throughout its length; it is attached to a rather small polygonal head. Phages $3 \mathrm{~B}$ and 6 (Pl. 4, figs. 26-30) are especially remarkable for the length of the tail, $3000 \AA$ is the largest yet found, and the head of a length equal to twice its width. Satisfactory micrographs of the head of phage $3 \mathrm{~B}$ have not been obtained but from examination of the shape of the empty head it is tentatively concluded that the intact particles resemble the drawing in Fig. 12. The terminal tail knobs are small in comparison to those of phage 187.

\section{(d) Streptococcus phage $3 \mathrm{ML}$ (Fig. 11, and Pl. 4, figs. 24, 25)}

This is a small phage of a shape not found previously. Its head shows no sharp angularity and its tail is devoid of sheath or neck. The tail in the DNA-less phage (Pl. 4, fig. 24) can be seen to be hollow. 
Group 3. Phages with very short tails, coli phage T3 (Fig. 10, and Pl. 4, figs. 3133) and Brucetla phage (Pl. 4, fig. 34)

Both these phages have polygonal heads, six-sided in plan view, $650 \AA$ across. They possess very short wedge-shaped tails, $140 \AA$ long, attached at one corner of the head. It is particularly interesting that the only Brucella phage available (Brinley Morgan et al. 1960) should be the only example of this morphological type to be described outside the coli-typhoid group.

\section{DISCUSSION}

The results shown here are primarily of morphological interest, but a detailed knowledge of phage morphology is essential before any attempt can be made to elucidate the mechanism of injection. It is obvious from the foregoing that phages which lack contractile sheaths must use some other means of penetrating the bacterial cell wall; this is at present obscure. A study of Table 1 (Dimensions) is of taxonomic interest. The present state of phage taxonomy is extremely confused, and it can be seen that neither pure morphology nor differences in host species can provide a complete answer as a method of classification. For example, if morphology were used, the group of phages resembling coli phage T2 would all be labelled as one species or type, but in fact they require different host cells. Morphology may well be a valuable aid of classification, however, and it can be seen that the different types studied here fall into fairly well-defined groups.

There are many questions to which the negative contrast method does not provide an answer, such as the shape of the head. It unfortunately only shows this in two dimensions and though a hexagonal outline is revealed it is not possible to state the geometric form which the head takes without a very high quality shadowed preparation using shadowing from two directions (Smith \& Williams, 1958). The only other way to elucidate the true head shape is to study the packing of subunits, but these are not visible in an organized state. There is no doubt that the negative contrast method can be varied considerably as suggested by Nixon (1960) and different embedding compounds used. This has been amply confirmed by the difference in appearance between the phosphotungstate and uranyl acetate preparations of T.5. The treatment of phage particles at different $\mathrm{pH}$ values and the subsequent study of their molecular structure is clearly the next step in the application of the method. There is little doubt that the technique is an extremely valuable aid in phage research and should enable a great deal of fundamental knowledge to be obtained about this form of virus.

With the exception of the S13 phage (Hall, Maclean \& Tessman, 1959), of which the 'tail' if any is as yet undisclosed, all phages have in common a 'head' and a 'tail', the sizes and shapes of which can vary considerably. There seems no reason to doubt that the head contains the DNA of the phage and that the tail, at least in cases where there is a knob or base-plate, carries at its distal end the device which enables the phage to adsorb specifically to its host cell.

Phage tail structures vary enormously in their complexity from the elaborate contractile sheath, base-plate and fibres of Group 1 to the apparent simplicity of Group 3. This simplicity may be only apparent and if higher resolution could be obtained a complexity at molecular level equal to Group 1 might be found. However, 
apart from Group 3 in which detail is lacking, all phage tails are basically tubes, the length of which may differ from strain to strain. The tube is not visibly hollow unless the head has lost its DNA which implies that the head DNA, when it departs under the condition of the preparation technique, is completely ejected from both head and tail. This is seen in Pl. 1, figs. 4, 6, 9, and Pl. 2, figs. 10, 14, and others. The only information available about the fine structure of this tube is that given in Pl. 2, fig. 10, showing T 5 treated with uranyl acetate. A banded structure with a periodicity of $44 \AA$ is visible. In some phages the tail tube is surrounded with either a contractile (Group 1) or a non-contractile sheath (Group 2, some members). The non-contractile sheath is visible in Pl. 3, figs. 14 and 22, where it does not cover the first part of the tube as it emerges from the head. Certain phages, notably T 1 (Pl. 3, fig. 17), T 5 (Pl. 2, fig. 10) and 3 ML (Pl. 4, fig. 25), show no sign of comparable thickening of, or sheath around, the tube.

The contractile sheath of phage $\mathrm{C} 4$ ( $\mathrm{Pl} .1$, figs. 3, 4) is similar to that of T2 (fully described by Brenner et al. 1959), especially in showing a periodicity of $30 \AA$. Brenner et al. believed the $\mathbf{T} 2$ sheath to be a helix; if so, the $\mathrm{C} 4$ sheath is probably also a helix.

Tails may be terminated in three ways. The end-plate with prongs, as described by Brenner et al. (1959), for phage T2, also well shown in $11 \mathrm{~F} \mathrm{(Pl.} \mathrm{1,} \mathrm{figs.} \mathrm{1,} \mathrm{2)} \mathrm{and}$ very markedly in Vi 1 (PI. 1, fig. 8), is the most complex terminal device. In Pl. 1, figs. 6-8 the end-plate is seen still attached to the contractile sheath even after contraction has taken place.

The second device for the termination of phage tails is the knob apparent in Pl. 3, figs. 18-22, and Pl. 4, figs. 28 and 29. This knob appears to be polygonal, it is hexagonal in plan view when derived from phage 187 (Pl. 3, fig. 23). In this case the knobs were sometimes found attached to linear structures about equal to the phage tail in length but of reduced diameter. These structures were first observed in staphylococcus phage $\mathbf{K}$ by Hotchin (1954) who believed them to be plugs which fitted into the hollow tail of the phage. The present studies have not yet been able to confirm or deny this suggestion.

Finally the tails may terminate in what may be a rounded or pointed tip (Pl. 2, fig. 10, and Pl. 3, fig. 17). Plate 3, fig. 16, shows a tail tip of this sort turned upwards and viewed end-on.

The heads of the phages in all cases, except $3 \mathrm{ML}$ (Pl. 4, figs. 24, 25) show or have shown in other pictures a hexagonal appearance in plan view. Most are regular hexagons but a few are slightly elongated (Group 1) and some (Pl. 4, figs. 27-29) show considerable elongation. The angularity frequently survives the loss of the DNA, as shown in Pl. 1, figs. 6, 7, Pl. 2, fig. 13, and Pl. 3, figs. 21 and 22, indicating a degree of rigidity in the head membrane and suggesting that the angular shape of the phage head is due to the arrangement of the subunits from which it is built, rather than to the packing of the DNA which it surrounds.

The fine structure of the head membrane is never visible in the phosphotungstate-treated specimens, but in the case of the uranyl acetate-treated phage T5 (Pl. 2, figs. 10-13) the size and shape of the subunits forming the membrane can just be discerned. They appear to be short, hollow cylinders about $100 \AA$ long and $50 \AA$ in diameter and are disorganized, presumably due to the staining procedure. 
A membraneous structure is visible within the main structural envelope of the head of some phages, particularly in Pl. 3, figs. 14, 16, 17 and 19-21, where the DNA has been discharged. It suggests a collapsible elastic membrane normally surrounding the DNA just inside the rigid structural membrane of the head and as this is always seen attached to the origin of the tail tube there is the possibility that this membrane, in tension, provides the driving force to expel the DNA from the phage particle during infection of a cell.

The authors wish to thank Mr R. W. Horne for valuable suggestions. One of them (D. E. B.) is grateful to Dr T. E. Allibone, F.R.S., Director of the Research Laboratory, Associated Electrical Industries, for permission to publish this paper.

\section{REFERENCES}

Brenner, S., Streisinger, G., Horne, R. W., Champe, S. P., Barnet"r, L., Benzer, S. \& REES, M. W. (1959). Structural components of bacteriophage. J. mol. Biol. 1, 281.

Brinley Morgan, W. J., Kay, D. \& Bradley, D. E. (1960). Brucella bacteriophage. Nature, Lond. (in the Press).

Fildes, P. \& KAY, D. (1955). The rate of adsorption of bacteriophage by rough and smooth strains of Salmonella typhi. Brit. J. exp. Path. 36, 534.

Frldes, P. \& KAY, D. (1957). Tryptophan as a bacteriophage adsorption factor. Brit. $J$. exp. Path. 38, 563.

Hatr, C. E., Maclean, E. C. \& Tessman, I. (1959). Structure and dimensions of bacteriophage $\phi \times 174$ from electron microscopy. J. mol. Biol. $1,192$.

Horne, R. W., Brenner, S., Waterson, A. P. \& Wildy, P. (1959). The icosahedral form of an adenovirus. J. mol. Biol. 1,84 .

Hotchin, J. E. (1954). The purification and electron microscopical examination of the structure of staphylococcal bacteriophage K. J. gen. Microbiol. 10, 250.

$K_{A Y}$, D. (1959). The inhibition of bacteriophage multiplication by proflavine and its reversal by certain polyamines. Biochem. $J .73,149$.

Nixon, H. L. (1960). Conference of Electron Microscopy Group of Institute of Physics, Exeter, 1959, Summarized Proceedings. Brit. J. appl. Phys. 11, 22.

Smith, K. M. \& Williams, R. C. (1958). Insect viruses and their structure. Endeavour, $17,12$.

\section{EXPLANATION OF PLATES}

Note. 'Active' indicates that DNA is present in the head and 'inactive' denotes that it is not and that the particle is presumably non-infective. 'PTA' indicates the phosphotungstate method and 'PMA' the phosphomolybdate method. Scale marks represent $500 \AA$.

\section{Plate 1}

Figs. 1, 2. Typhoid phage $11 \mathrm{~F}$, active, PTA method, $\times 250,000$.

Fig. 3. Typhoid phage C4, active, PMA method, $\times 250,000$.

Fig. 4. Typhoid phage C4, inactive, PMA method, $\times 250,000$.

Fig. 5. Typhoid phage 2, active, PTA method, $\times 250,000$.

Figs. 6, 7. Typhoid phage 2 , inactive, PTA method, $\times 250,000$.

Fig. 8. Typhoid phage Vi1, active and inactive, PTA method, $\times 145,000$.

Fig. 9. Coli phage 'I'5, inactive, PTA method, $\times 250,000$.

Plate 2

Fig. 10. Coli phage T5, inactive, uranyl acetate method, $\times 250,000$.

Figs. 11-13. Coli phage T5, inactive, uranyl acetate method, $\times 500,000$. 
Journal of General Microbiology, Vol. 23, No. 3

Plate 1
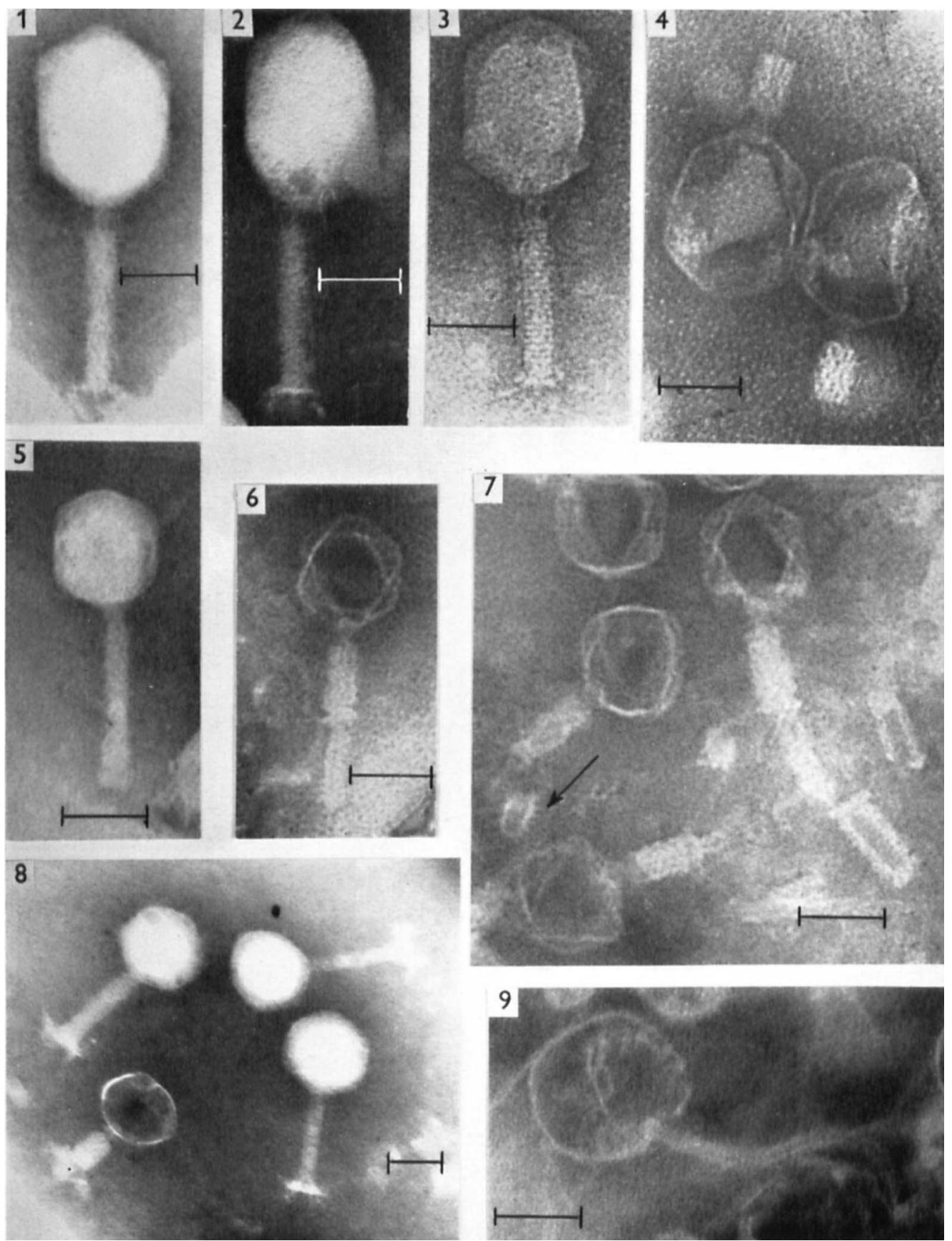

D. E. BRADLEY AND D. KAY

(Facing p. 562) 
Journal of General Microbiology, Vol. 23, No. 3

Plate 2
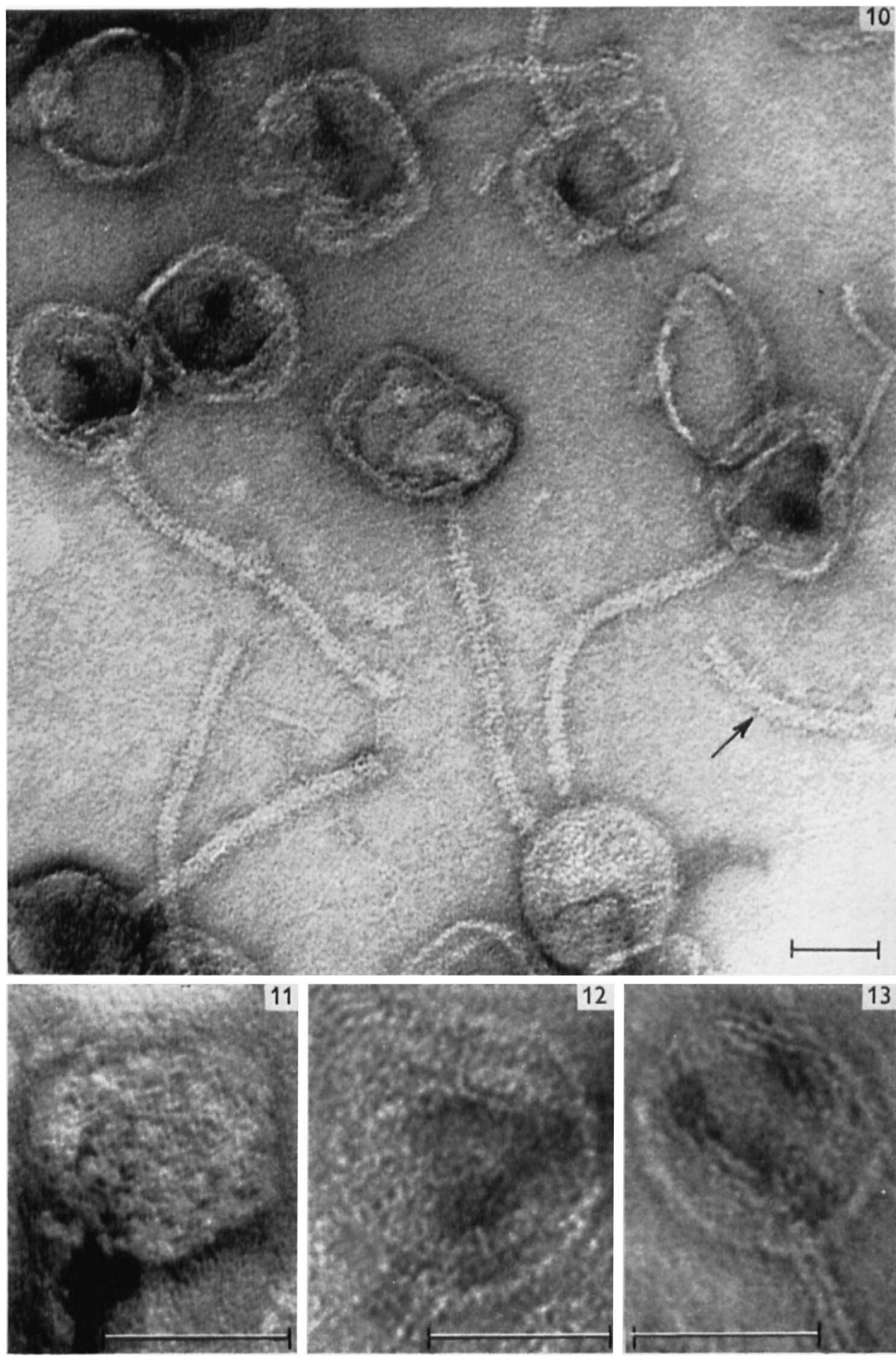

D. E. BRADLEY AND D. KAY 
Journal of General Microbiology, Vol. 23, No. 3

Plate 3

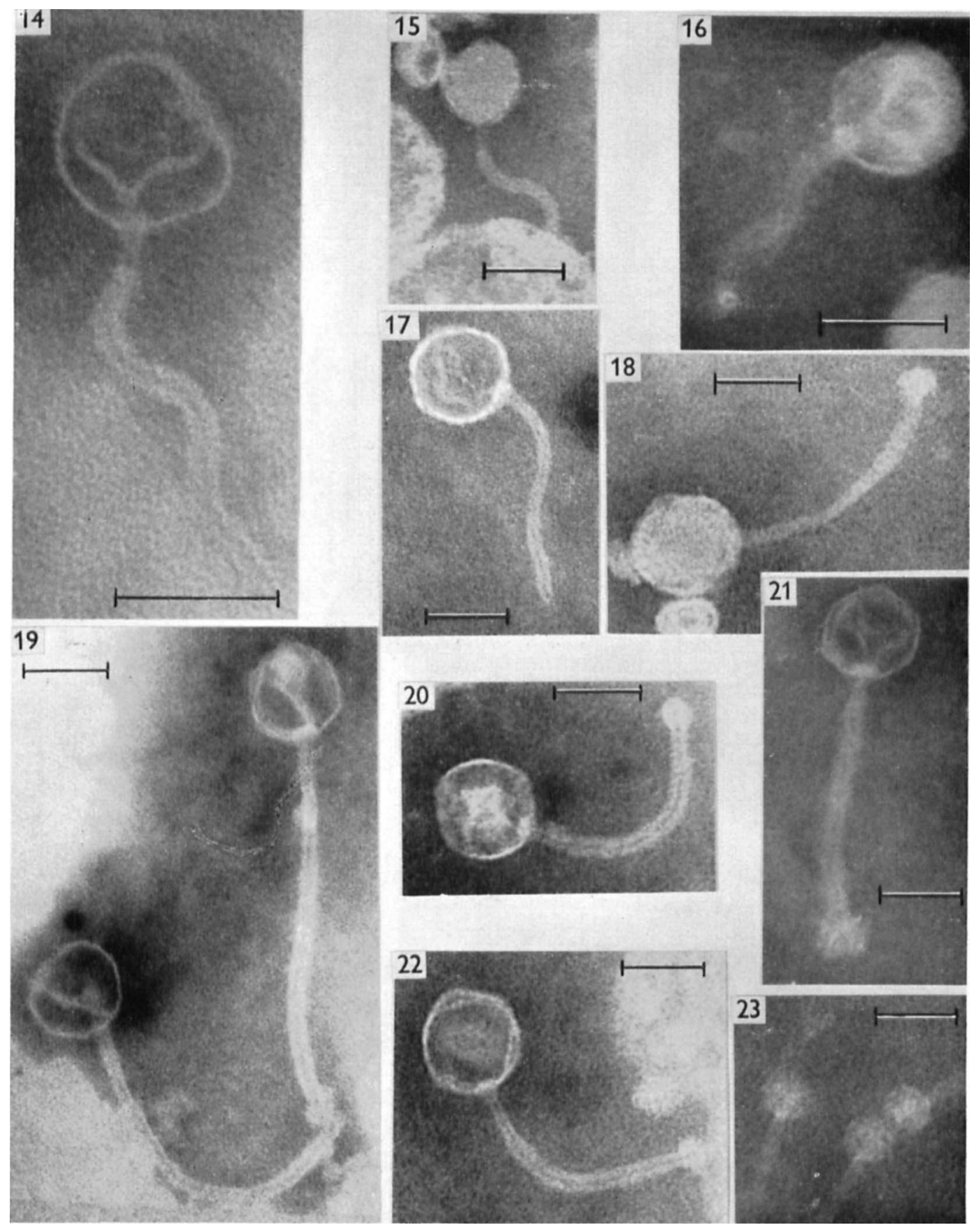

D. E. BRADLEY AND D. KAY 
Journal of General Microbiology, Vol. 23, No. 3
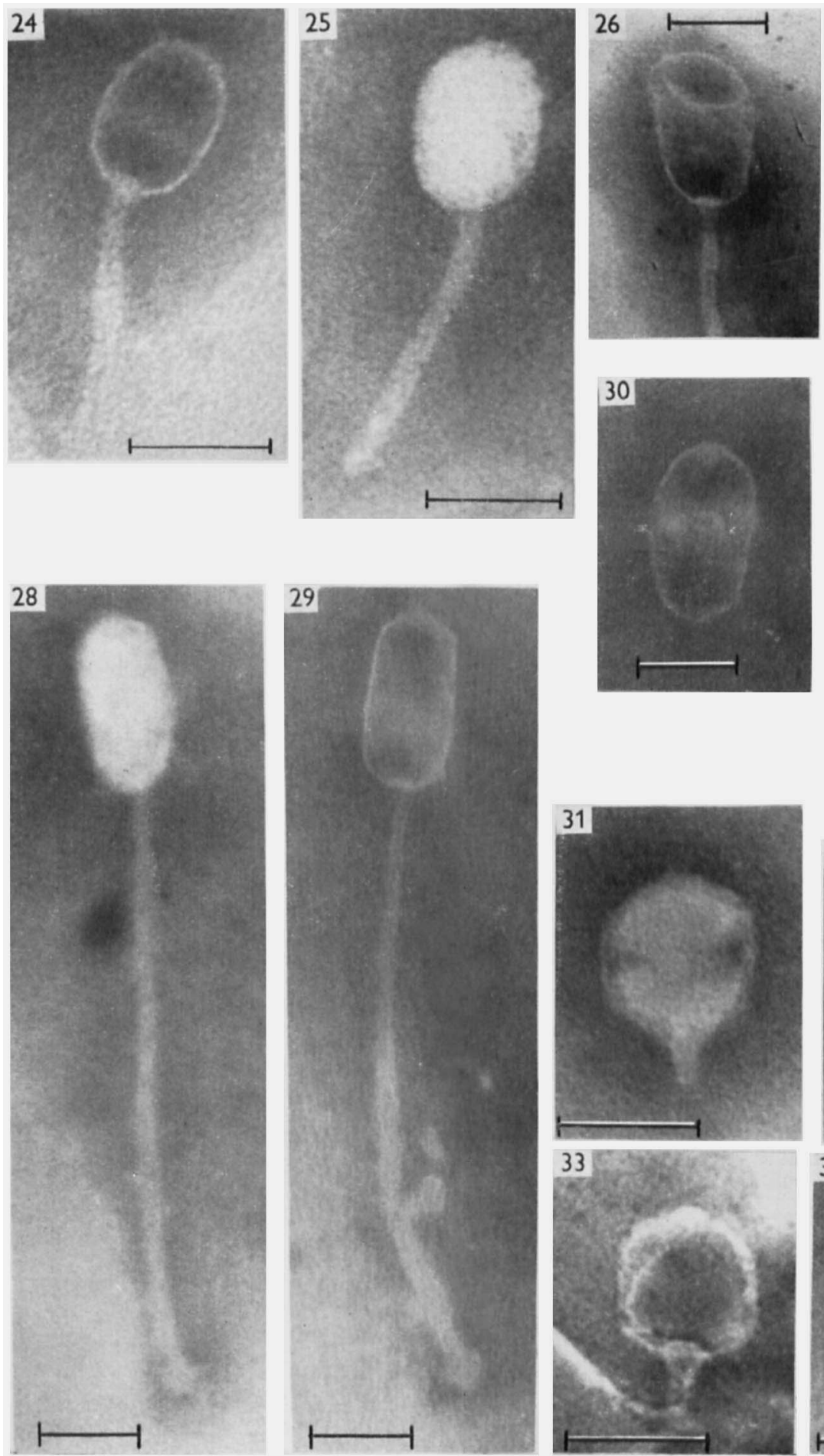

31
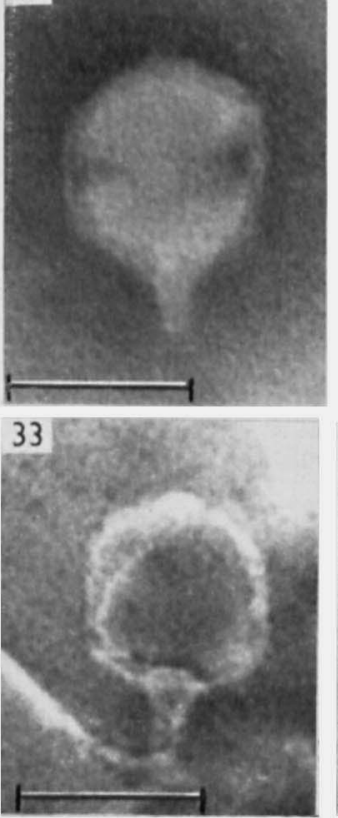
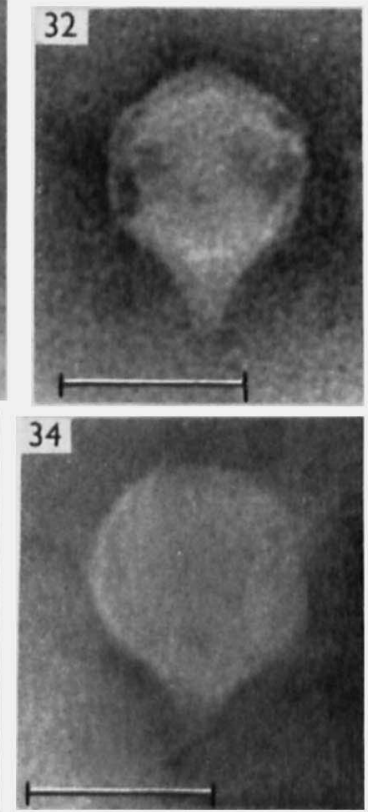

Plate 4

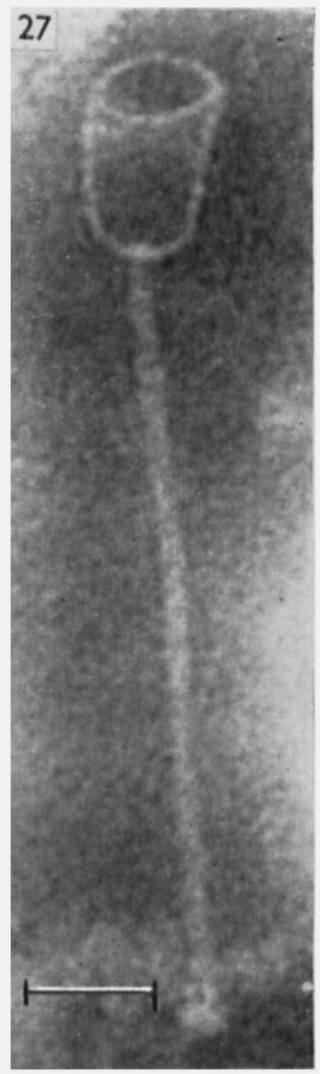

D. E. BRADLEY AND D. KAY 
Plate 3

Fig. 14. Typhoid phage S1 BL, inactive, PMA method, $\times 500,000$.

Fig. 15. Typhoid phage S1 BL, active, PMA method, $\times 250,000$.

Fig. 16. Coli phage T1, inactive, PTA method, $\times 375,000$.

Fig. 17. Coli phage T1, active, PTA method, $\times 250,000$.

Fig. 18. Pseudomonas phage Pc, active, PTA method, $\times 250,000$.

Fig. 19. Staphylococcus phage 77 , inactive, PTA method, $\times 250,000$.

Fig. 20. Pseudomonas phage Pc, inactive, PTA method, $\times 250,000$.

Fig. 21. Staphylococcus phage 187, inactive, PTA method, $\times 250,000$.

Fig. 22. Pseudomonas phage Pc, inactive, P'TA method, $\times 250,000$.

Fig. 23. Staphylococcus phage 187, tail knobs, PTA method, $\times 250,000$.

\section{Plate 4}

Fig. 24. Streptococcus phage $3 \mathrm{ML}$, inactive, PTA method, $\times \mathbf{3 7 5 , 0 0 0}$.

Fig. 25. Streptococcus phage $3 \mathrm{ML}$, active, PTA method, $\times 375,000$.

Figs. 26, 27. Staphylococcus phage 3 B, inactive, PTA method, $\times 250,000$.

Fig. 28. Staphylococcus phage 6 , active, PTA method, $\times 250,000$.

Figs. 29, 30. Staphylococcus phage 6, inactive, PTA method, $\times 250,000$.

Figs. 31 and 32. Coli phage T3, active, PTA method, $\times \mathbf{3 7 5 , 0 0 0}$.

Fig. 33. Coli phage T3, inactive, PTA method, $\times 375,000$.

Fig. 34. Brucella phage, active, PTA method, $\times 375,000$. 